\title{
Time Constants of $h$ Current in Layer II Stellate Cells Differ along the Dorsal to Ventral Axis of Medial Entorhinal Cortex
}

\author{
Lisa M. Giocomo and Michael E. Hasselmo \\ Center for Memory and Brain, Program in Neuroscience and Department of Psychology, Boston University, Boston, Massachusetts 02215
}

Chronic recordings in the medial entorhinal cortex of behaving rats have found grid cells, neurons that fire when the rat is in a hexagonal array of locations. Grid cells recorded at different dorsal-ventral anatomical positions show systematic changes in size and spacing of firing fields. To test possible mechanisms underlying these differences, we analyzed properties of the hyperpolarization-activated cation current $I_{\mathrm{h}}$ in voltage-clamp recordings from stellate cells in entorhinal slices from different dorsal-ventral locations. The time constant of $\mathrm{h}$ current was significantly different between dorsal and ventral neurons. The time constant of $\mathrm{h}$ current correlated with membrane potential oscillation frequency and the time constant of the sag potential in the same neurons. Differences in $\mathrm{h}$ current could underlie differences in membrane potential oscillation properties and contribute to grid cell periodicity along the dorsal-ventral axis of medial entorhinal cortex.

Key words: h current; grid cells; entorhinal cortex; stellate cells; subthreshold oscillations; HCN subunit

\section{Introduction}

The entorhinal cortex serves as the primary gateway between higher-order neocortical areas and the hippocampus (McNaughton et al., 2006; Witter and Moser, 2006). Unit recording data has demonstrated that, as a rat explores an open environment, many cells in medial entorhinal cortex (mEC) fire in spatially specific locations that repeat at regular intervals forming a hexagonal grid pattern of firing fields (Hafting et al., 2005; Sargolini et al., 2006; Barry et al., 2007; Fyhn et al., 2007). These "grid cells" show systematic differences in spatial properties along the dorsal-ventral axis of medial entorhinal cortex. Larger grid field size and spacing is observed in the more ventral portions compared with the more dorsal portions of medial entorhinal cortex (Hafting et al., 2005; Sargolini et al., 2006).

In vitro research has recently shown that the intrinsic properties of neurons in the same medial entorhinal region also systematically change along the dorsal-ventral axis (Giocomo et al., 2007). Stellate cells in the superficial layers of medial entorhinal cortex are characterized by an intrinsic membrane potential oscillation that appears when the cell is near firing threshold (Alonso and Llinás, 1989; Alonso and Klink, 1993; Dickson et al., 2000). The frequency of the intrinsic membrane potential oscillation, as well as the stellate cell resonance frequency, changes systematically along the dorsal-ventral axis of medial entorhinal

\footnotetext{
Received July 9, 2008; accepted Aug. 11, 2008.

This work was supported by National Institute of Mental Health (NIMH) Grants MH61492 and MH60013; Silvio 0 Conte Center NIMH Grant MH71702; National Science Foundation, Science of Learning Center, Social, Behavioral, and Economic Sciences Grant 0354378; and National Institute on Drug Abuse Grant DA16454 (part of the Collaborative Research in Computational Neuroscience program).

Correspondence should be addressed to Lisa M. Giocomo, Center for Memory and Brain, Program in Neuroscience and Department of Psychology, Boston University, 2 Cummington Street, Boston, MA 02215. E-mail: giocomo@gmail.com.

DOI:10.1523/JNEUROSCI.3196-08.2008

Copyright $\odot 2008$ Society for Neuroscience $\quad 0270-6474 / 08 / 289414-12 \$ 15.00 / 0$
}

cortex (Giocomo et al., 2007). Computational models have shown how grid fields could arise from interference of membrane potential oscillations within single neurons (Burgess et al., 2007), and show how the change in membrane potential oscillation frequency could underlie the systematic change in grid field size and spacing observed in recording data from behaving rats (Burgess et al., 2007; Giocomo et al., 2007; Hasselmo et al., 2007).

Subthreshold membrane potential oscillations have been shown to arise from the interaction of membrane currents (White et al., 1995). In layer II of medial entorhinal cortex, the oscillations appear to arise from interactions of two currents (Dickson et al., 2000; Fransén et al., 2004), a hyperpolarization-activated cation current $\left(I_{\mathrm{h}}\right)$ and a persistent sodium current $(\mathrm{NaP})$. The interplay between these two currents allows the cell to oscillate when the membrane potential is near firing threshold. The difference in frequency of subthreshold oscillations may be attributable to a systematic variation in the activation kinetics of $I_{\mathrm{h}}$, as suggested by the already reported difference in the time constant of the sag of the membrane potential (Giocomo et al., 2007). Previous research has demonstrated that the kinetics of $I_{\mathrm{h}}$ depend on what subunits (HCN1 and/or HCN2) make up the channel (Chen et al., 2001), and immunohistochemical staining has shown labeling for both HCN1 and HCN2 in rat medial entorhinal cortex (Notomi and Shigemoto, 2004). We hypothesized that differences in the activation kinetics of $I_{\mathrm{h}}$ would underlie differences in physiological properties of neurons along the dorsal-ventral axis of medial entorhinal cortex. In addition, differences in $h$ current kinetics could contribute to differences in grid cell properties through other mechanisms proposed to underlie grid cell firing responses (Burak and Fiete, 2006; Fuhs and Touretzky, 2006; McNaughton et al., 2006).

\section{Materials and Methods}

Slice preparation

Physiological recordings were performed on brain slices from young (17-23 d of age), male and female Long-Evans rats (Charles River Lab- 
oratories), obtained after anesthetization with isoflurane (Abbot Laboratories) and decapitation. The Institutional Animal Care and Use Committee at Boston University approved all experimental techniques. The brain was rapidly removed under $4^{\circ} \mathrm{C}$ artificial CSF (ACSF) (SigmaAldrich) [ACSF concentrations (in $\mathrm{mm}$ ): $126.0 \mathrm{NaCl}, 3 \mathrm{KCl}, 2 \mathrm{MgSO}_{4}$, 10.0 dextrose, $26.0 \mathrm{NaHCO}_{3}, 1.25 \mathrm{NaH}_{2} \mathrm{PO}_{4}, 2 \mathrm{CaCl}_{2}$ ] oxygenated by bubbling $95 \% \mathrm{O}_{2} / 5 \% \mathrm{CO}_{2}$ through the solution.

Whole-cell patch-clamp recordings were conducted in horizontal brain slices. To control for slice health, the brain was mounted on either its ventral surface (top-down cut) or dorsal surface (bottom-up cut), on separate days, to allow slicing in different directions. The average age of the animal for all recordings was $19.4 \pm 0.2(n=110)$. There was not a significant relationship between the age of the animal and the frequency of oscillations (see supplemental Fig. 1, available at www.jneurosci.org as supplemental material) as determined by the Spearman's rank correlation coefficient $(\rho=-0.044 ; p=0.73)$ or the time constant at a voltage step to $-70 \mathrm{mV}$ (see supplemental Fig. 1, available at www.jneurosci.org as supplemental material) as determined by the Spearman's rank correlation coefficient $(\rho=0.30 ; p=0.16)$.

The slicing technique used to determine the depth of each slice has been described previously (Giocomo et al., 2007). Briefly, 400- $\mu$ m-thick slices were placed in separate holding chambers after the brain was cut into quarters through the corpus collosum and at $\sim 4 \mathrm{~mm}$ from the rostral surface of the brain ( $-4 \mathrm{~mm}$ bregma). After slicing, the depth of the last slice was measured at $\sim 2 \mathrm{~mm}$ lateral from the midline and -4 $\mathrm{mm}$ bregma, to determine the location of all slices.

After slicing, slices were stored at $31^{\circ} \mathrm{C}$ for $30 \mathrm{~min}$ and then at room temperature for $30 \mathrm{~min}$. Slices were transferred to a submerged recording chamber with continuously flowing ACSF kept at $37.0 \pm 0.5^{\circ} \mathrm{C}$. Patch pipettes (3-7 M $\Omega$ ) were pulled from $10 \mathrm{~cm}$ borosilicate glass capillary tubes (Sutter Instrument) with a Sutter Instrument model P-87 pipette puller and filled with the following (in mM): $120 \mathrm{~K}$-gluconate, $10 \mathrm{HEPES}$, 0.2 EGTA, $20 \mathrm{KCl}, 2 \mathrm{MgCl}, 7$ diTrisPhCr, $4 \mathrm{Na}_{2} \mathrm{ATP}$, and 0.3 Tris-GTP, $\mathrm{pH}$ adjusted to 7.3 with $\mathrm{KOH}$. The intracellular solution contained $0.1 \%$ biocytin for morphological identification and staining of the cells. Cells were visualized on an upright microscope (Axioskop; Carl Zeiss) equipped with a $40 \times$ water-immersion objective lenses (Carl Zeiss). With this equipment, the location and laminar distribution of EC cells is easily discernable (Dickson and Alonso, 1997; Dickson et al., 2000). Tight seals $(>1 \mathrm{G} \Omega$ ) between the recording pipette and cell membrane were formed and ruptured with negative pressure. Recordings were amplified by a Multiclamp 700B (Molecular Devices) or in some initial cases, an Axoclamp 2.0A. Capacitance neutralization and bridge balance were applied accordingly. Current-clamp data were filtered at $10 \mathrm{kHz}$ and voltage-clamp data at $2 \mathrm{kHz}$. Series resistances were usually on the order of $10 \mathrm{~m} \Omega$ and compensated by 60 to $80 \%$. Data was digitized with a Digidata 1440 (Molecular Devices) at a sampling frequency of $20 \mathrm{kHz}(50$ $\mu \mathrm{s})$. Signals were acquired using a Pentium-based computer running Clampex 10.0 software (Molecular Devices). After completion of experiments, slices were fixed in $4 \%$ paraformadehyde for later staining. For all solutions, the liquid junction potential was estimated between 5 and 6 $\mathrm{mV}$ using the technique of Neher (1992) and Dickson et al. (2000). Membrane potential values reported here do not contain this correction.

Of 149 cells, 110 were identified as stellate cells based on electrophysiological criteria including the presence of "sag" potential and membrane potential oscillations. These electrophysiological criteria were confirmed by morphological identification of biocytin-stained cells. Morphological identification was performed for $49 \%$ of stellates used to determine the time constant kinetics of $I_{\mathrm{h}}$. Staining also confirmed the location of $54 \%$ of stellates in layer II of medial entorhinal cortex. Supplemental Figure 2 (available at www.jneurosci.org as supplemental material) illustrates examples of morphologically identified stellate cells along the dorsal-ventral axis of medial entorhinal cortex. Of the 110 stellate cells, 57 came from the dorsal-most portion of medial entorhinal cortex (defined here as $3.8-4.9$ bregma) and 53 came from the more ventral portion of medial entorhinal cortex (defined here as $5.0-7.0 \mathrm{~mm}$ bregma). Coordinates were based on those of Paxinos and Watson (1998). All cells used were held for $\geq 15 \mathrm{~min}$, had an input resistance of $\geq 35 \mathrm{M} \Omega$, an action poten- tial height of $\geq 50 \mathrm{mV}$ from threshold to peak, and a resting potential of less than or equal to $-50 \mathrm{mV}$.

\section{Staining for intracellular biocytin}

Biocytin-filled cells were stained using previously described methods (Hamam et al., 2002; Tahvildari and Alonso, 2005) to identify the morphology of cells. Tissue slices fixed in $4 \%$ paraformaldehyde were removed and washed (three times for $5 \mathrm{~min}$ each time) in $0.1 \mathrm{M}$ sodium phosphate buffer $(\mathrm{NaPB})$, and processed without additional sectioning. Incubation for $30 \mathrm{~min}$ in PHT $(0.1 \mathrm{M} \mathrm{NaPB}, 0.2 \%$ gelatin, $0.25 \%$ Triton $\mathrm{X}-100$ ) blocked the nonspecific binding sites. The slices were then labeled with an avidin-biotin-horseradish peroxidase complex (Vector Laboratories) and left overnight in PHT. The next day, slices were washed in PHT, first in brief washes (five times for 3 min each time), and then in a longer wash (six times for $1 \mathrm{~h}$ each time) with the last wash continuing overnight. On the third day, slices were washed three times for $10 \mathrm{~min}$ each time in $0.1 \mathrm{~m}$ Tris-buffered saline, $\mathrm{pH}$ adjusted to 7.6 with $\mathrm{HCl}$, and then transferred to a $3,3^{\prime}$-diaminobenzidine solution (DAB substrate solution) (Vector Laboratories). When the desired staining was reached, the $\mathrm{DAB}$ reaction was stopped by washing the slices in Tris-buffered saline (three times for 10 min each time). The slices were mounted on gelatinized glass slides, left to air dry for $5 \mathrm{~min}$, and coverslipped using Mowiol (Sigma-Aldrich). The slides were allowed to dry in the dark and later imaged using an Olympus microscope (Spencer Scientific) and Image-Pro Plus (Media Cybernetics) software. Morphological determination of stellate versus pyramidal cell was based on previous characterization of stellate and nonstellate cells in layer II of entorhinal cortex (Klink and Alonso, 1997).

\section{Solutions}

For all experimental solutions, $2 \mathrm{~mm}$ kynurenic acid and $100 \mu \mathrm{M}$ picrotoxin, were added to block synaptic transmission (Sigma-Aldrich). Additional solutions were perfused for at least $10 \mathrm{~min}$ before data collection began. Solutions used for voltage-clamp protocols all contained $1 \mu \mathrm{M}$ tetrodotoxin (TTX), to block voltage-activated sodium currents; $2 \mathrm{~mm}$ $\mathrm{BaCl}_{2}$, which has been shown to potently block potassium currents (Standen and Stanfield, 1978; Gómez-Lagunas, 1999; Walsh and Zhang, 2008); and $2 \mathrm{mM} \mathrm{CoCl}_{2}$, to block voltage-gated calcium channels (Hagiwara and Takahashi, 1967; Eckert and Lux, 1976). To block $I_{\mathrm{h}}, 100 \mu \mathrm{M}$ 4-ethylphenylamino-1,2-dimethyl-6-methylaminopyrimidinium chloride (ZD7288) (Tocris Bioscience) and in some cases $10 \mu \mathrm{M} Z \mathrm{ZD} 7288$ was added to the solution. The concentration of $100 \mu \mathrm{M}$ ZD7288 was based on previous research on the $\mathrm{h}$ current in entorhinal cortex, the hippocampus, and other cortical regions (Harris et al., 1994; Harris and Constanti, 1995; Maccaferri and McBain, 1996; Gasparini and DiFrancesco, 1997; Dickson et al., 2000; Gill et al., 2006; Inaba et al., 2006; Kretschmannova et al., 2006; Zhang et al., 2006). To block the M current $10 \mu \mathrm{M}$ XE991 [10,10-bis(4-pyridinylmethyl)-9(10 H)-anthracenone dihydrochloride] (Tocris Bioscience) was added to the solution. A modified solution was used to isolate $I_{\mathrm{h}}$ for the tail current protocol and included the following: $80 \mathrm{~mm} \mathrm{NaCl}, 40 \mathrm{~mm}$ TEA-Cl (tetraethylammonium chloride), $5 \mathrm{~mm} \mathrm{KCl}, 4 \mathrm{~mm}$ 4-AP (4-aminopyridine), $2 \mathrm{~mm} \mathrm{MgCl}_{2}$, $2 \mathrm{mM} \mathrm{BaCl}_{2}, 2 \mathrm{~mm} \mathrm{CoCl} 2,2 \mathrm{~mm} \mathrm{CaCl}, 0.2 \mathrm{~mm} \mathrm{CdCl}_{2}, 26 \mathrm{~mm} \mathrm{NaH}_{2} \mathrm{CO}_{3}$, $10 \mathrm{~mm}$ glucose, and $1 \mu \mathrm{M}$ TTX (Sigma-Aldrich; Tocris Bioscience).

\section{Data analysis}

Analysis and statistics. Clampfit 10.0 (Molecular Devices), MATLAB (Mathworks), and Excel (Microsoft) were used for data analysis. While the cell was at rest, the resistance was calculated by injecting 1-s-long hyperpolarizing current steps. Overall, the data collected did not show a normal distribution [as tested by the Kolmogorov-Smirnov (ks) test in MATLAB]. The Kolmogorov-Smirnov test function "kstest2" in MAT$\mathrm{LAB}$, which does not assume a Gaussian distribution of the data, was used to test differences between two samples of data from different populations (e.g., dorsal vs ventral cells). For time constants measured at multiple voltages and in different regions (dorsal vs ventral), the one-tailed Kruskal-Wallis test function "kruskalwallis," which does not assume a Gaussian distribution of the data, was used in MATLAB. The Spearman's rank correlation coefficient was determined for correlations using the "corr" function in MATLAB. For all statistical analysis, a value of $p<$ 
0.05 was considered significant. Regression lines were constructed using the least-squares method in Microsoft Excel and $r$ values are reported.

Frequency of subthreshold oscillation. Methods to determine the dominant frequency of membrane potential oscillations during current-clamp recording in stellate cells have been previously described (Giocomo et al., 2007). Briefly, continuous recordings were made and current was injected at a variety of levels (1-1000 pA) until the cell was near firing threshold. To analyze the frequency of subthreshold oscillations, an automated procedure in MATLAB analyzed segments of membrane potential recorded near firing threshold. The membrane potential recordings were divided into 3 -s-long windows that overlapped by $1.5 \mathrm{~s}$. Windows containing a spike were removed from the analysis. The maximum length of the recording analyzed was $186 \mathrm{~s}$, with a minimum of $10 \mathrm{~s}$. Each window of data was zero centered and autocorrelations on the window were performed using the xcorr function of MATLAB. The frequency was determined as the inverse of the interval from the central peak to the first side peak. The frequencies of the three windows with the highest difference between the amplitudes of the side peak and the trough between the two peaks were averaged and recorded as the results for the cell. After the automated process, all of the autocorrelation measurements were double checked by eye, and the measurement was corrected if the measurement of the first side peak was incorrect.

Sag analysis. The time course of $I_{\mathrm{h}}$ effects on membrane potential during current clamp was further analyzed by characterizing the sag observed during a hyperpolarizing current step (Alonso and Klink, 1993), in which an initial strong hyperpolarization decays to a more depolarized steady-state potential. The sag was analyzed for a subset of stellate cells $(n=59)$, which showed a prominent sag ending at the steady-state membrane potentials of interest $(-75.9$ to $-70 \mathrm{mV})$. Cells were held in current clamp at $-60 \mathrm{mV}$ and 3-s-long hyperpolarizing current injections were given at a range of amplitudes. The "NonlinearLeastSquares" method of MATLAB was used in combination with the function "exp2" of MATLAB to analyze the time constant of the sag. Current-clamp data were fitted with the following double exponential function:

$$
F=A_{1} e^{\left(-t / \tau_{1}\right)}+A_{2} e^{\left(-t / \tau_{2}\right)},
$$

where $A_{1}$ and $A_{2}$ are the amplitude of the fast $\left(\tau_{1}\right)$ and slow $\left(\tau_{2}\right)$ component of the sag, respectively. Sag potentials were used for the fitting, starting from the trough of the sag response ( $+7 \mathrm{~ms}$, to pass the trough) and ending before the end of the current pulse $(-4 \mathrm{~ms}$, to avoid any stimulation artifact). Time constants $\left(\tau_{1}\right.$ and $\left.\tau_{2}\right)$ were used in the subsequent analysis, and analysis was performed only on traces with an endpoint voltage of between -75.9 and $70.0 \mathrm{mV}$. For the scatterplots shown in Figure $7 B$, the $\tau_{1}$ for each cell was used from the trace whose endpoint was closest to $-70.0 \mathrm{mV}$.

Kinetics of $\mathrm{I}_{h}$. To determine the time course of activation and deactivation of $I_{\mathrm{h}}$, the cell was held at $-60 \mathrm{mV}$ in voltage clamp. In a control solution, hyperpolarizing (activation) and depolarizing (deactivation) voltage steps increasing in either 1 or $5 \mathrm{mV}$ steps to $-35 \mathrm{mV}$, were delivered for $1 \mathrm{~s}(n=2$ cells $), 1.5 \mathrm{~s}(n=11$ cells $)$, or $3 \mathrm{~s}(n=31$ cells $)$. The same voltage-clamp protocol was then run in the presence of the $I_{\mathrm{h}}$ blocker ZD7288. The trace acquired in the presence of ZD7288 was subtracted from the control trace, pharmacologically isolating $I_{\mathrm{h}}$. The subtracted traces were fit with a dual-exponential equation in MATLAB, to determine the fast and slow time constant of activation and deactivation, using the following equation:

$$
I_{h}(t)=A_{1} e^{\left(-t / \tau_{1}\right)}+A_{2} e^{\left(-t / \tau_{2}\right)}
$$

where $I_{\mathrm{h}}(t)$ is the total amplitude of the current at time $t$, and $A_{1}$ and $A_{2}$ are the respective amplitudes of the components with fast $\left(\tau_{1}\right)$ and slow $\left(\tau_{2}\right)$ time constants. The dual-exponential fit started $15 \mathrm{~ms}$ after the voltage step, to avoid capacitance transients. Fits ended at least $15 \mathrm{~ms}$ before the end of the voltage step and not $>1.5 \mathrm{~s}$ after the voltage step had been applied. The slow time constant was not used for the two cells whose voltage step was $1 \mathrm{~s}$ long. Goodness-of-fit statistics and the amplitudes of the fit were used to determine how well the dual exponential equation fit the experimental data. If the amplitude of the fit was negative (a value in a direction opposite of the expected value) or the root mean squared error was $>20$, the time constant value for that individual trace was removed from the analysis. In cases in which the amplitude indicated a poor fit, the start time was changed $\pm 6 \mathrm{~ms}$, in an attempt to derive a better fit. If a fit with the correct sign was achieved by changing the start time, it was checked by eye and the new time constant was used. Of the 394 individual fast time constants reported, only 17 of these were measured after changing the start time. For the slow time constant, two time 

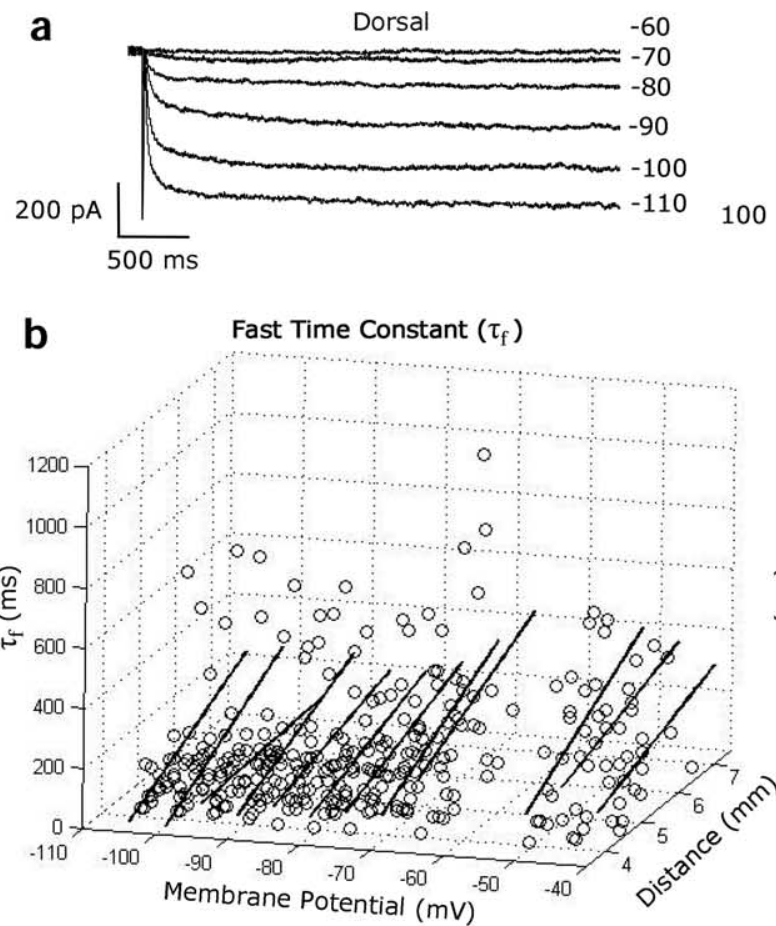

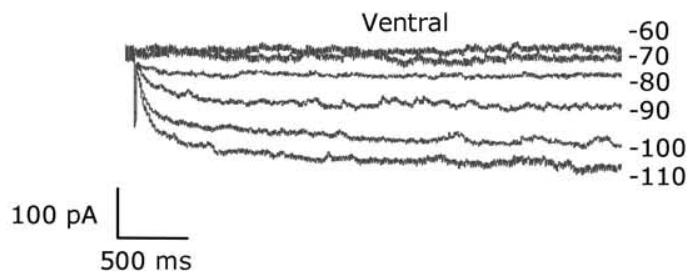

C Slow Time Constant $\left(\tau_{\mathrm{f}}\right)$

d
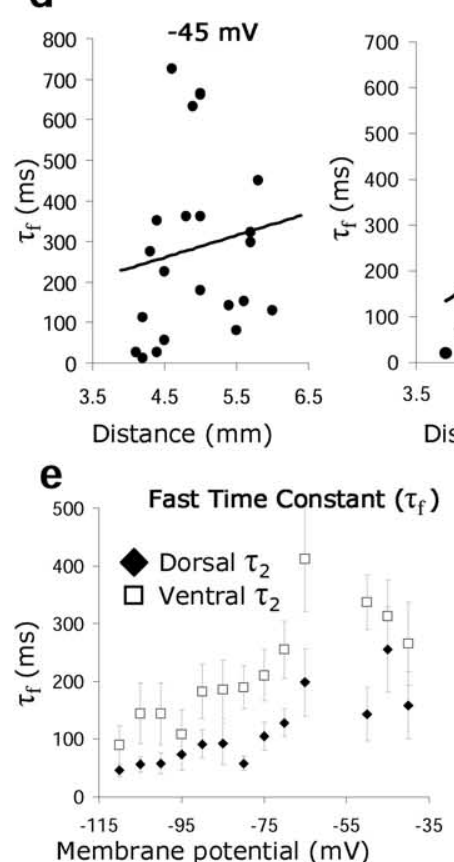

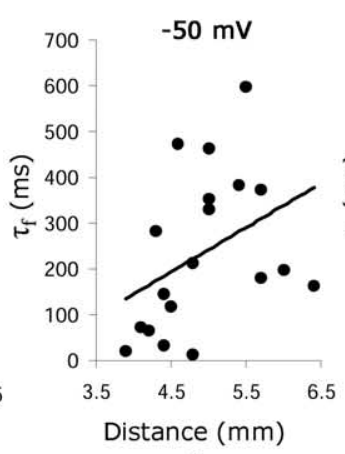

f

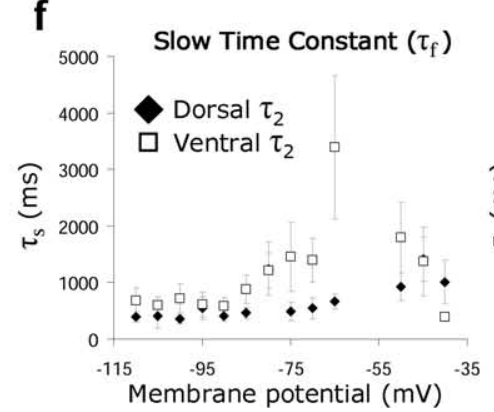

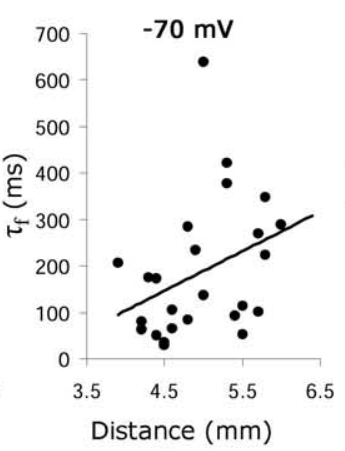

a
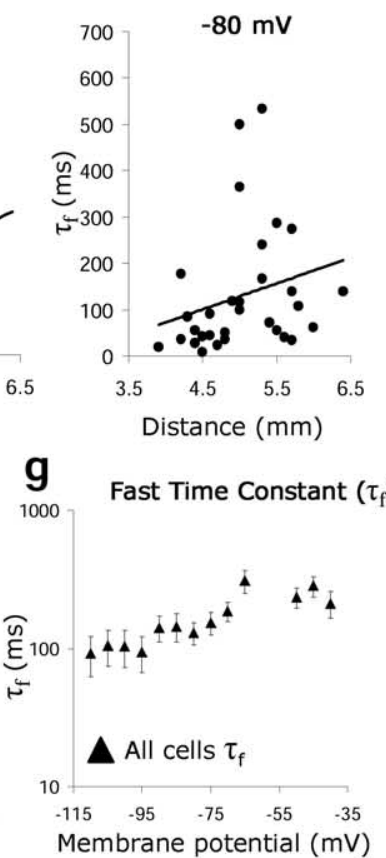

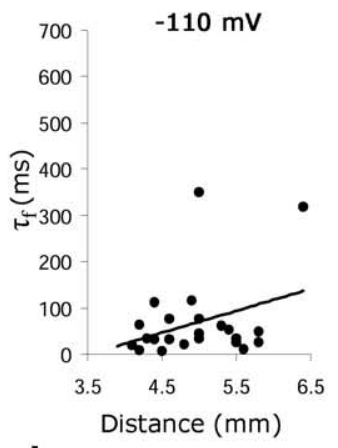

h

Figure 2. Time constant of $/ \mathrm{h}$ activation and deactivation changes along the dorsal-ventral axis of medial entorhinal cortex. Error bars indicate SEM. $\boldsymbol{a}$, Subtracted current traces from two cells, one more dorsal (black, left) and one more ventral (gray, right) during hyperpolarizing steps in voltage clamp. $\boldsymbol{b}$, The fast time constant of $I_{h}$ is faster in more dorsal portions of $\mathrm{mEC}$ compared with more ventral portions at multiple voltages. $\boldsymbol{c}$, The slow time constant of $I_{\mathrm{h}}$ is faster in more dorsal portions of $\mathrm{mEC}$ compared with more ventral portions at multiple voltages. $\boldsymbol{d}$, Fast time constant of $I_{h}$ increases from dorsal to ventral medial entorhinal cortex (distance from dorsal surface, in millimeters) at multiple voltages (from left to right: $-45,-50,-70$, and $-80 \mathrm{mV}$ ). The time constant of $I_{\mathrm{h}}$ begins to saturate at very hyperpolarized potentials and the change in the time constant of $I_{\mathrm{h}}$ along the dorsal-ventral axis has a smaller slope (far right, $-110 \mathrm{mV}$ ). $\boldsymbol{e}$, Average fast time constant of $I_{\mathrm{h}}$ is faster in dorsal (black diamonds) compared with ventral (open squares) cells across all voltages tested. $f$, Average slow time constant of $I_{h}$ is faster in dorsal (black diamonds) compared with ventral (open squares) cells across almost all voltages tested. $\boldsymbol{g}$, Average fast time constant of $I_{\mathrm{h}}$ for all stellate cells. $\boldsymbol{h}$, Average fast time constant of $I_{\mathrm{h}}$ for all pyramidal-like cells.

constant data points $>22,000 \mathrm{~ms}$ were removed. Consistent with other studies, time constants were not measured at the holding potential $(-60$ $\mathrm{mV}$ ) or the next depolarized step $(-55 \mathrm{mV})$ from the holding potential, because the trace flattens and the fit does not accurately measure the time constant of $I_{\mathrm{h}}$ and instead gives very large time constant values.

To determine the steady-state activation of $I_{\mathrm{h}}$, a modified solution was used to isolate the current (see above, Solutions). The cell was held at
$-40 \mathrm{mV}$ in voltage clamp and 3-s-long hyperpolarizing voltage steps were applied. After the voltage step, the cell was brought back to $-40 \mathrm{mV}$ and a tail current was observed. The tail current was measured relative to starting baseline and normalized to the maximum current measured. Curves were well fit with the following Boltzmann equation:

$$
I(V)=1 /\left\{1+e^{\left[\left(V-V_{1 / 2}\right) / k\right]}\right\},
$$


Table 1. Fast time constant of $I_{\mathrm{h}}$ at multiple membrane potentials

\begin{tabular}{lllllllrrrrr}
\hline Holding $(\mathrm{mV})$ & Mean $(\mathrm{ms})$ & SEM $(\mathrm{ms})$ & Dorsal $(\mathrm{ms})$ & SEM (ms) & Ventral (ms) & SEM (ms) & Slope & Intercept & $r$ & $\rho$ & $p$ \\
\hline-40 & 211.94 & 46.96 & 158.39 & 58.27 & 265.49 & 71.16 & 56.61 & -67.89 & 0.21 & 0.37 & 0.20 \\
-45 & 284.3 & 47.73 & 255.35 & 74.31 & 313.25 & 62.27 & 284.30 & 15.04 & 0.14 & 0.33 & 0.14 \\
-50 & 235.22 & 39.35 & 143.26 & 45.92 & 337.40 & 47.31 & 235.22 & -242.12 & 0.39 & 0.51 & 0.02 \\
-65 & 309.05 & 57.78 & 198.04 & 58.43 & 412.13 & 90.84 & 78.12 & -82.43 & 0.16 & 0.22 & 0.28 \\
-70 & 186.14 & 29.46 & 122.10 & 23.06 & 255.52 & 49.76 & 85.03 & -235.96 & 0.35 & 0.48 & 0.03 \\
-75 & 153.94 & 27.79 & 88.82 & 20.04 & 210.38 & 44.64 & 77.78 & -237.48 & 0.30 & 0.41 & 0.03 \\
-80 & 130.16 & 24.19 & 58.01 & 12.17 & 189.58 & 37.60 & 55.86 & -150.95 & 0.25 & 0.42 & 0.02 \\
-85 & 145.08 & 33.44 & 92.10 & 36.01 & 185.61 & 50.96 & 44.62 & -78.92 & 0.14 & 0.29 & 0.12 \\
-90 & 141.68 & 29.38 & 89.29 & 23.16 & 182.43 & 47.50 & 73.56 & -230.51 & 0.27 & 0.23 & 0.21 \\
-95 & 94.24 & 27.19 & 74.11 & 27.95 & 108.46 & 42.40 & 9.69 & 45.57 & 0.04 & 0.14 & 0.57 \\
-100 & 104.08 & 30.72 & 58.10 & 17.64 & 143.94 & 54.05 & 89.46 & -341.92 & 0.34 & 0.18 & 0.36 \\
-105 & 105.12 & 30.09 & 56.21 & 12.95 & 144.87 & 52.14 & 79.50 & -295.96 & 0.30 & 0.14 & 0.47 \\
-110 & 92.00 & 29.56 & 45.74 & 10.83 & 134.69 & 54.27 & 70.33 & -257.38 & 0.28 & 0.21 & 0.31 \\
\hline
\end{tabular}

For each membrane voltage, the mean time constant of $l_{\mathrm{h}}$ for all cells, the mean time constant of $I_{\mathrm{h}}$ for dorsal cells $\left(3.8-4.9 \mathrm{~mm}\right.$ from the dorsal surface), the mean time constant of $I_{\mathrm{h}}$ for ventral cells $(5.0-7.0 \mathrm{~mm}$ from the dorsal surface) the slope of the regression line, the intercept of the regression line, the $r$ value, the $\rho$ value determined from the Spearman's rank correlation coefficient, and the corresponding $p$ value are shown.

where $I(V)$ is the current at voltage $V, V$ is the voltage during the hyperpolarizing step, $V_{1 / 2}$ is the midpoint voltage of activation, and $k$ is the slope of the fit.

To determine the reversal potential of $I_{\mathrm{h}}$, the cell was clamped at -80 $\mathrm{mV}$ in a control solution and depolarizing voltage steps in $5 \mathrm{mV}$ steps to $-35 \mathrm{mV}$ were delivered for $3 \mathrm{~s}$. The same protocol was then run in the presence of ZD7288 and the instantaneous $I-V$ relationship was measured in both conditions, plotted, and fit with a linear regression line. The intersection of the two $I-V$ relationships was extrapolated from the linear fits to determine the reversal potential. Using this technique, the reversal potential was estimated at $-19.31 \pm 8.93 \mathrm{mV}(\mathrm{SEM})(n=6)$, a potential similar to that previously reported for $I_{\mathrm{h}}$ in entorhinal stellate neurons (Dickson et al., 2000).

\section{Results}

Time constant of $I_{\mathrm{h}}$

Voltage-clamp recordings from layer II stellate cells show significant differences in the time constants of the $\mathrm{h}$ current along the dorsal to ventral axis of medial entorhinal cortex. To measure the time constant of $I_{\mathrm{h}}$, current traces collected during voltage-clamp recording in the presence of the $h$ current blocker ZD7288 were subtracted from current traces taken during voltage clamp in a control solution (see Materials and Methods) (Fig. 1). Figure $2 a$ shows examples of a subtracted trace for two individual cells. The time course of change in current is best fitted with a dualexponential function yielding two time constants, fast and slow. Plotting of time constants at different voltages (in millivolts) versus distance from the dorsal surface of the brain shows that the fast time constant of $I_{\mathrm{h}}$ changed systematically from dorsal locations to ventral locations in medial entorhinal cortex at all voltages tested, with faster time constants for $I_{\mathrm{h}}$ in more dorsal compared with more ventral stellate cells for the fast time constant (Fig. $2 b$ ) and slow time constant (Fig. $2 c$ ). Figure $2 d$ illustrates examples of the linear fit to the fast time constant of $I_{\mathrm{h}}$ versus dorsal-ventral location at a voltage step to $-45,-50,-70$, and $-80 \mathrm{mV}$. Table 1 lists the slopes, $r$ values, and $p$ values for fits at each voltage step. Slow time constants also changed from dorsal to ventral entorhinal cortex, but were more variable than the fast time constants. Supplemental Figure 3 (available at www. jneurosci.org as supplemental material) illustrates examples of the linear change in the slow time constant of $I_{\mathrm{h}}$ at a voltage step to $-70 \mathrm{mV}(r=0.30$; slope, $542.33 ; \rho=0.40 ; p=0.12)$ and -75 $\mathrm{mV}(r=0.31$; slope, $918.27 ; \rho=0.42 ; p=0.05)$. At very hyperpolarized potentials, such as $-110 \mathrm{mV}$, both the fast and slow ( $r=0.05$; slope, 54.71) time constants of $I_{\mathrm{h}}$ begin to saturate (Chen et al., 2007) and the slope of the change in the time constant of $I_{\mathrm{h}}$ decreased (Fig. $2 d$; supplemental Fig. 3, available at www.jneurosci.org as supplemental material). The fast time con- stant of $I_{\mathrm{h}}$ current activation and deactivation was systematically and significantly faster in dorsal (i.e., $3.8-4.9 \mathrm{~mm}$ from dorsal surface) compared with ventral cells (i.e., $5.0-6.5 \mathrm{~mm}$ from dorsal surface) as determined by the Kruskal-Wallis (KW) test $\left(\chi^{2}=\right.$ $29.2 ; p<0.0001$ ) (Fig. 2e). This dorsal to ventral difference appears at a range of holding voltages, on top of a systematic change in time constant across voltages $\left(\chi^{2}=74.05 ; p<0.0001\right)$. The slow time constant of $I_{\mathrm{h}}$ activation and deactivation was also significantly faster in dorsal compared with ventral cells as determined by the KW test $\left(\chi^{2}=7.96 ; p=0.005\right)$ (Fig. $\left.2 f\right)$, on top of a systematic change in time constant across voltages $\left(\chi^{2}=37.78\right.$; $p=0.002)$. The slower time constant for $I_{\mathrm{h}}$ activation and deactivation in ventral neurons compared with dorsal neurons suggests that the kinetics of $I_{\mathrm{h}}$ differ along the dorsal-ventral axis of medial entorhinal cortex and could contribute to other intrinsic cellular differences such as subthreshold membrane oscillations, resonance frequency, and the sag potential (Giocomo et al., 2007).

In addition to stellate cells, layer II of medial entorhinal cortex also contains pyramidal-like cells (Alonso and Klink, 1993), which show a substantially slower and smaller amount of $I_{\mathrm{h}}$. The fast time constant for the stellate cells (Fig. $2 g$ ) is faster than the fast time constant for pyramidal neurons (Fig. $2 h$ ), supporting previous research indicating slower kinetics of $I_{\mathrm{h}}$ in nonstellate layer II neurons (Alonso and Klink, 1993).

\section{Properties of stellate cells along the dorsal-ventral axis}

Many of the electrophysiological properties of stellate cells during current-clamp recording were similar in neurons across the range of dorsal and ventral portions of medial entorhinal cortex. The resting membrane potential (mean \pm SEM, $-61.8 \pm 0.50$ $\mathrm{mV}$, and $n=110$; slope, $-0.31 ; r=0.03 ; \rho=-0.006 ; p=0.95)$, action potential threshold (mean \pm SEM, $-48.2 \pm 0.41 \mathrm{mV}$; slope, $-0.24 ; r=0.03 ; \rho=0.003 ; p=0.97)$, and peak action potential voltage (mean \pm SEM, $24.97 \pm 0.89 \mathrm{mV}$; slope, -1.27 ; $r=0.03 ; \rho=-0.063 ; p=0.51)$ did not significantly correlate with the location of the cell along the dorsal-ventral axis as determined by the Spearman's rank correlation coefficient. The resistance of the neuron at its resting potential did differ along the dorsal to ventral axis (mean \pm SEM, $93.81 \pm 4.57 \mathrm{~m} \Omega$; slope, $6.39 ; r=0.08 ; \rho=0.22 ; p=0.02$ ) (supplemental Fig. 4 , available at www.jneurosci.org as supplemental material).

\section{Steady-state activation of $I_{\mathrm{h}}$}

To determine the steady-state activation of $I_{\mathrm{h}}$ in currentclamp recording, a modified solution was perfused to isolate $I_{\mathrm{h}}$ 
a

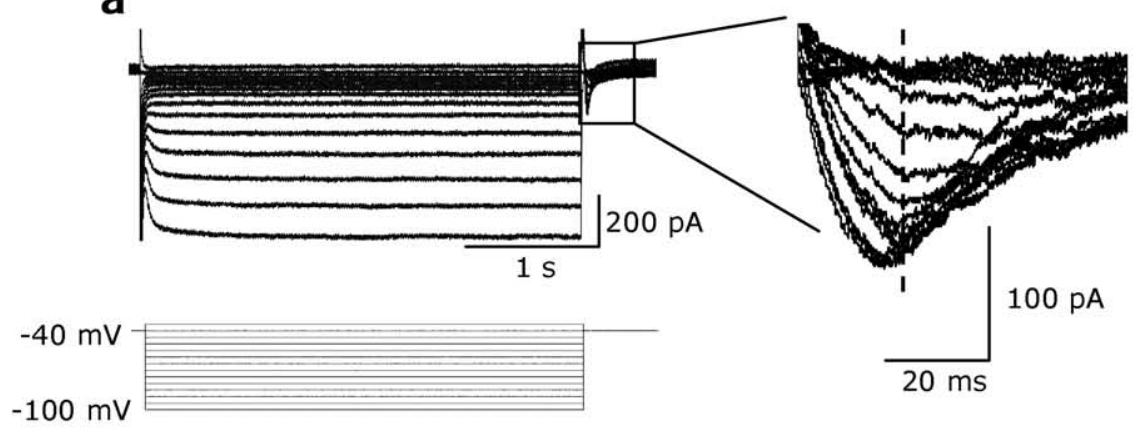

b
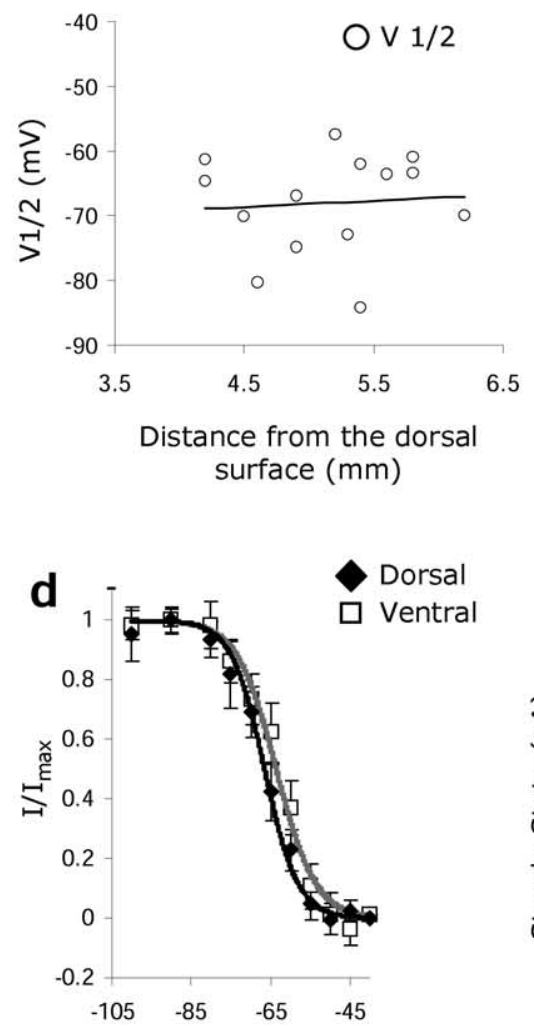

Membrane potential ( $\mathrm{mV}$ )

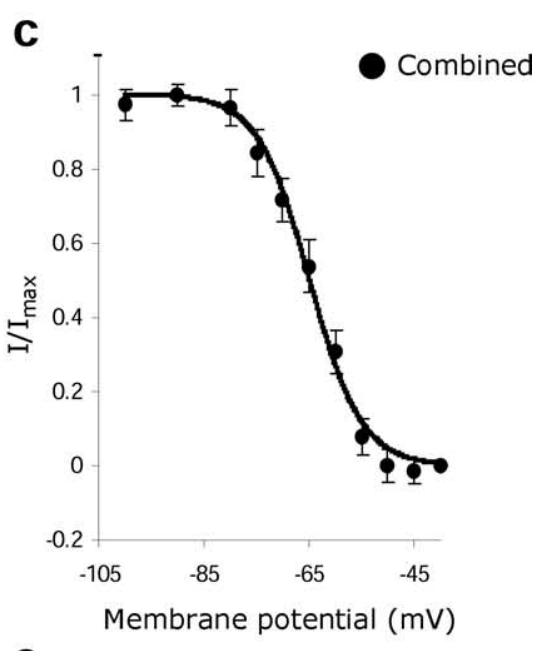

e

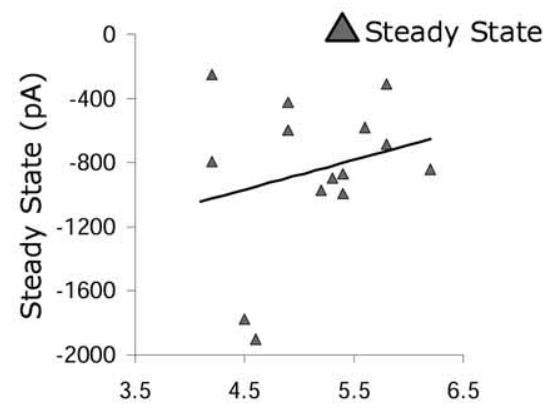

Distance from the dorsal surface $(\mathrm{mm})$

Figure 3. Steady-state activation is similar in stellate cells along the dorsal-ventral axis. Error bars indicate SEM. $\boldsymbol{a}$, The neuron is clamped at $-40 \mathrm{mV}$ and a 3 -s-long hyperpolarizing voltage step delivered (left). When the voltage is stepped back up to -40 $\mathrm{mV}$, a tail current is observed (right). Current is measured (dotted line) relative to baseline and normalized to the maximum current measured. $\boldsymbol{b}$, The $V_{1 / 2}$ did not systematically change along the dorsal-ventral axis of medial entorhinal cortex. $\boldsymbol{c}$, Average steady-state activation curve for all stellate cells combined. $\boldsymbol{d}$, Steady-state activation curves were similar in dorsal compared with ventral neurons, with ventral cells showing a slightly more depolarized $V_{1 / 2}$. $\boldsymbol{e}$, Steady-state amplitude (in picoamperes) for cells did not significantly differ along the dorsal-ventral axis of medial entorhinal cortex.

(see Materials and Methods). The amplitude of the tail current was used to determine the steady-state activation (Fig. $3 a$ ) for cells along the dorsal to ventral axis. Figure $3 b$ illustrates the midpoint voltage of activation for all cells relative to their location along the dorsal-ventral axis. When all cells were combined, regardless of their location, the midpoint voltage of activation was $-68.08 \pm 2.09 \mathrm{mV}$ with a slope of $6.33 \pm 0.64$ $\mathrm{mV}(n=14)$ (Fig. $3 c)$ and the midpoint voltage of activation did not significantly change along the dorsal to ventral axis of $\mathrm{mEC}$, as determined by the Spearman's rank correlation coef- ficient (slope, $0.96 ; r=0.08 ; \rho=0.15$; $p=0.60)$. The half-maximal voltage of activation for dorsal cells was $-69.68 \pm$ $2.48 \mathrm{mV}$ with a slope of $6.34 \pm 0.88 \mathrm{mV}$ $(n=6)$. The half-maximal voltage of activation for ventral cells was a slightly more depolarized value of $-66.80 \pm$ 3.04 with a slope of $6.34 \pm 0.88 \mathrm{mV}(n=$ 8 ). The half-maximal voltage of activation was not significantly different between dorsal and ventral cells $(p=0.35$; $k=0.48)$ as determined by the ks test (Fig. $3 d$ ). Previous data has shown that heteromeric HCN1/HCN2 channels expressed in oocytes have similar steadystate activation curves to homomeric HCN1 channels, although the time constant of $I_{\mathrm{h}}$ significantly differs between the two channel types (Chen et al., 2001). The steady-state activation of $I_{\mathrm{h}}$ in dorsal versus ventral neurons suggests that, if different ratios of HCN1 to HCN2 subunits change the time constant of the current, the change in ratios does not affect the steady-state activation levels of the current.

Steady-state current amplitude was measured by holding the cell in voltage clamp at $-40 \mathrm{mV}$ and stepping to -120 $\mathrm{mV}$ in the presence of the modified $I_{\mathrm{h}}$ isolation solution (see Materials and Methods), a technique similar to that used to measure $I_{\mathrm{h}}$ density in hippocampal pyramidal neurons (Magee, 1998). The steady-state current amplitude, measured at the end of a 3-s-long hyperpolarizing voltage step to $-120 \mathrm{mV}$, did not significantly change along the dorsal-ventral axis, as determined by the Spearman's rank correlation coefficient (slope, $186.31 ; r=0.24 ; \rho=0.11 ; p=$ 0.72 ) and the mean steady-state amplitude was not significantly different between dorsal and ventral neurons as determined by the ks test (mean \pm SEM, dorsal, $-957.71 \pm 288.89 \mathrm{pA}$ and $n=6$; ventral, $-768.69 \pm 82.08 \mathrm{pA}$ and $n=8$; $p=0.75 ; k=0.33)$. Figure $3 e$ plots the steady-state amplitude for individual cells relative to their dorsal-ventral location. The similar steady-state current amplitude between dorsal and ventral neurons suggests that the density of $I_{\mathrm{h}}$ channels is similar in the soma of stellate cells from dorsal to ventral medial entorhinal cortex.

\section{Subthreshold membrane potential oscillations}

Experimental and computational research (Dickson et al., 2000; Fransén et al., 2004) indicates that the hyperpolarization-activated cation current $I_{\mathrm{h}}$ plays a critical role in generating subthreshold membrane potential oscillations near firing threshold. As shown previously (Dickson et al., 2000), membrane potential oscillations recorded in cur- 
rent clamp decreased in amplitude and frequency in the presence of the $I_{\mathrm{h}}$ blocker ZD7288 (Fig. 4) in all cells tested at a concentrations of $10 \mu \mathrm{M}(4$ of $n=4)$ and at $100 \mu \mathrm{M}(4$ of $n=4)$. Blockers of the $M$ current do not interfere with subthreshold membrane oscillations observed in layer II stellate cells (Yoshida and Alonso, 2007) (see supplemental Fig. 5, available at www.jneurosci.org as supplemental material).

Computational models that use the kinetics of $I_{\mathrm{h}}$ to generate subthreshold oscillations depend on the fast time constant of $I_{\mathrm{h}}$ activation and deactivation to pace the frequency of the subthreshold oscillations (Dickson et al., 2000; Fransén et al., 2004). Our data show a systematic correlation between the fast time constants observed in voltage clamp and the membrane potential oscillation frequency observed in current clamp. Figure 5 shows examples from six stellate cells (located along the dorsalventral axis) of a 3-s-long sample of subthreshold oscillations at an approximate membrane potential of $-50 \mathrm{mV}$ (Fig. $5 a)$, the subtracted traces used to determine the time constant of $I_{\mathrm{h}}$ (Fig. $5 b$ ), and the corresponding time constants of $I_{\mathrm{h}}$ determined from the subtracted traces (Fig. 5c).

In this study, the frequency of subthreshold membrane potential oscillations in stellate cells systematically decreased along the dorsal-ventral axis of medial entorhinal cortex, a result consistent with previously published reports (Giocomo et al., 2007). At a membrane potential of approximately $-50 \mathrm{mV}$, the frequency of subthreshold oscillations changed signifi-

cantly from higher frequencies in neurons from the dorsal region to lower frequencies in neurons from the ventral region of medial entorhinal cortex (slope, $-1.3 ; r=0.39 ; \rho=-0.38 ; p=0.0016$ ) as determined by the Spearman's rank correlation coefficient.

The frequency of membrane potentials in current clamp differs at different mean voltages. At $-45 \mathrm{mV}$, many neurons began to spike rapidly, but some had spike-free periods that were long enough to observe subthreshold oscillations. At a membrane potential of approximately $-45 \mathrm{mV}$, the frequency of the oscillations changed from higher frequencies in dorsal to lower frequencies in ventral cells and the difference approached significance (slope, $-3.0 ; r=0.44 ; \rho=-0.34 ; p=$ $0.15)$. A subset of stellate cells $(n=40)$ oscillated robustly at the more hyperpolarized membrane potential of $-55 \mathrm{mV}$; however, the difference in frequency along the dorsal to ventral axis was not significant at this voltage (slope, $-0.45 ; r=$ $0.12 ; \rho=-0.2 ; p=0.18$ ). Figure $6 a$ illustrates the change in the frequency of subthreshold oscillations relative to their dorsal-ventral location with higher frequency oscillations in dorsal compared with ventral neurons, at -45 and $-50 \mathrm{mV}$ and the apparent lack of change in frequency at the more hyperpolarized membrane potential of $-55 \mathrm{mV}$.
The correlation between membrane potential oscillation frequency and $I_{\mathrm{h}}$ time constants appears across the full population of recorded neurons. As shown in Figure 6b, the frequency of the subthreshold oscillations at $-50 \mathrm{mV}$ across a population of cells was very significantly correlated with the time constant of $I_{\mathrm{h}}$ at a membrane holding potential of -45 $\mathrm{mV}(r=0.53$; slope, $-0.003 \mathrm{~Hz} / \mathrm{ms} ; \rho=-0.68 ; p=0.01)$ (Fig. $6 b 1),-50 \mathrm{mV}(r=0.76$; slope, $-0.007 \mathrm{~Hz} / \mathrm{ms} ; \rho=-0.76 ; p=$ 0.002 ) (Fig. 6b2), and $-65 \mathrm{mV}(r=0.59$; slope, $-0.003 \mathrm{~Hz} /$ $\mathrm{ms} ; \rho=-0.72 ; p=0.0007$ ) (Fig. 6b3). At more hyperpolarized voltage steps, the time constant of $I_{\mathrm{h}}$ activation decreased and the data points became more clustered together (Fig. 6c). As shown in Figure 6b2, the largest $r$ value was observed when the fast time constant of $I_{\mathrm{h}}$ at $-50 \mathrm{mV}$ was correlated with the frequency of subthreshold oscillations at $-50 \mathrm{mV}$. However, only a subset of neurons showed oscillatory activity at $-50 \mathrm{mV}$ and also had a measurable time constant at $-50 \mathrm{mV}$. To look at the correlation across a larger number of neurons, the average time constant of $I_{\mathrm{h}}$ at potentials near the oscillation potential $(-65,-50$, and $-45 \mathrm{mV})$ was investigated for cells that had a measurable time constant at two or all of the three potentials. Figure $6 d$ illustrates the strong and significant cor- 
a

$5.4 \mathrm{~Hz}: 4.2 \mathrm{~mm}$

(1)

$6.5 \mathrm{~Hz}: 4.4 \mathrm{~mm}$

mintam

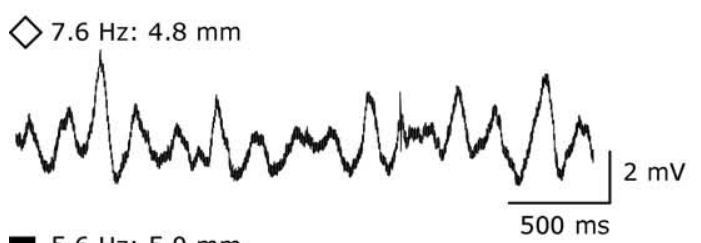

$5.6 \mathrm{~Hz}: 5.0 \mathrm{~mm}$

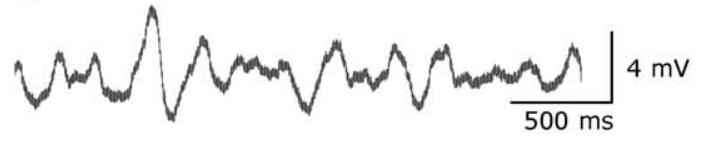

$2.4 \mathrm{~Hz}: 5.0 \mathrm{~mm}$

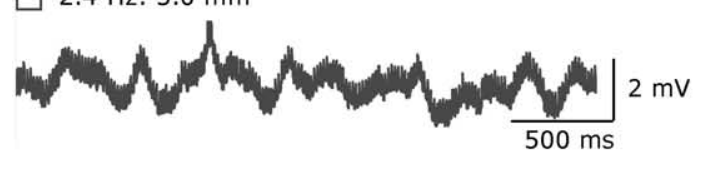

$4.3 \mathrm{~Hz}: 5.4 \mathrm{~mm}$

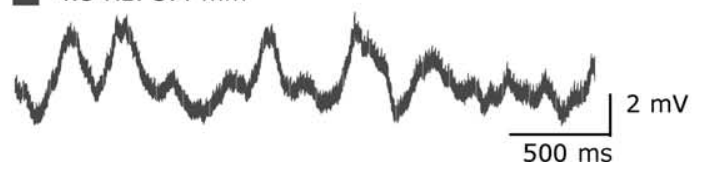

b
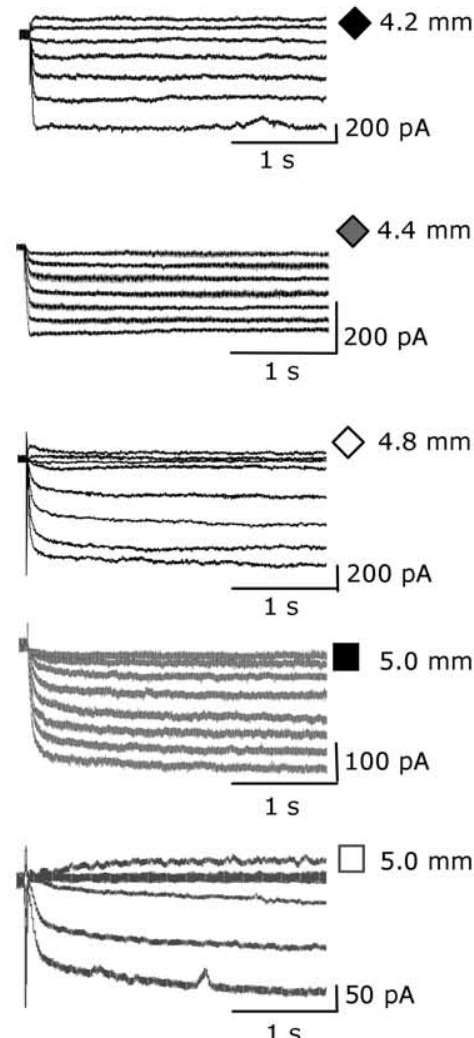

$5.4 \mathrm{~mm}$

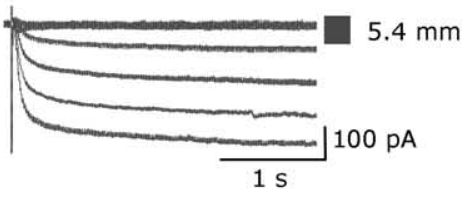

C 1000

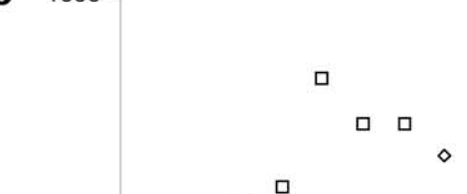

Figure 5. Frequency of subthreshold membrane oscillations correlates with time constant of $I_{\mathrm{h}}$. Data are shown for six neurons located along the dorsal to ventral axis of medial entorhinal cortex. For each cell, $\boldsymbol{a}$ shows a $3 \mathrm{~s}$ sample of membrane potential oscillations at $-50 \mathrm{mV}, \boldsymbol{b}$ shows the corresponding isolated $/ \mathrm{h}$ voltage-clamp trace, and $\boldsymbol{c}$ shows time constants derived from trace $\boldsymbol{b}$. The distance from the dorsal surface (the dorsal-ventral location) and the measured oscillation frequency is shown above the oscillation trace for each cell in $\boldsymbol{a}$.

relation between the frequency of subthreshold membrane potential oscillations in current clamp at voltages near $-50 \mathrm{mV}$ and the average time constant of $I_{\mathrm{h}}$ in voltage clamp at voltages near threshold $(r=0.56$; slope, $-0.006 \mathrm{~Hz} / \mathrm{ms} ; \rho=-0.81 ; p=0.00003)$. However, the average time constant of $I_{\mathrm{h}}$ in voltage clamp at voltages near threshold does not correlate with membrane potential oscillations in current clamp at voltages near $-55 \mathrm{mV}(r=0.10$; slope, 0.0008 ; $\rho=$ $-0.13 ; p=0.71)$. This suggests that the change in the time constant of $I_{\mathrm{h}}$ is critical for pacing oscillations at or near threshold but may play a smaller role in generating oscillations at lower membrane voltages (supplemental Fig. 6, available at www.jneurosci.org as supplemental material).

\section{Sag potential}

The sag potential, a depolarizing shift in the membrane potential observed during a hyperpolarizing current injection, also correlates with the activation of $I_{\mathrm{h}}$ (Dickson et al., 2000; Nolan et al., 2007) (Fig. 7). The fast time constant $\left(\tau_{1}\right)$ of the sag potential changed along the dorsal to ventral axis of medial entorhinal cortex at a membrane potential of -75 to $-70 \mathrm{mV}$ $(r=0.32$; slope, $12.36 ; \rho=0.35 ; p=0.02)$, with faster time constants in dorsal cells compared with ventral cells (Giocomo et al., 2007) (Fig. 7b). As shown in Figure $7 c$, the time constants of sag potentials in current clamp at these steady-state membrane potentials also correlated with the frequency of subthreshold membrane potential oscillations during current-clamp recordings near $-50 \mathrm{mV}(r=0.48$; slope, $-0.0435 ; \rho=-0.44 ; p=0.03)$. As shown in Figure $7 d$, the time constant of the sag at a steady-state membrane potential of -70 to $-75 \mathrm{mV}$ trended toward a correlation with the time constant of $I_{\mathrm{h}}$ at a voltage step to $-45 \mathrm{mV}(r=0.49$; slope, 5.30; $\rho=0.43 ; p=0.11),-50 \mathrm{mV}(r=0.49$; slope, $5.30 ; \rho=$ $0.6 ; p=0.07)$, and significantly correlated with the average of time constant from these two voltage steps $(r=0.55$; slope, 4.63; $\rho=0.35 ; p=0.02)$. However, the comparison of a single time constant of the sag to a single time constant of $I_{\mathrm{h}}$ may contribute to the weaker correlations between the sag and the time constant of $I_{\mathrm{h}}$ compared with those between the subthreshold oscillation frequency and the time constant of $I_{\mathrm{h}}$. Together, these data suggest that the time constant of $I_{\mathrm{h}}$ measured in voltage clamp correlates with the time constant of the sag potential measured in current clamp, and both of these time constants correlate with the frequency of subthreshold oscillations measured in current clamp at voltages just below firing threshold.

\section{Discussion}

These data demonstrate a systematic change in the kinetics of $I_{\mathrm{h}}$ activation and deactivation in voltage-clamp recordings 


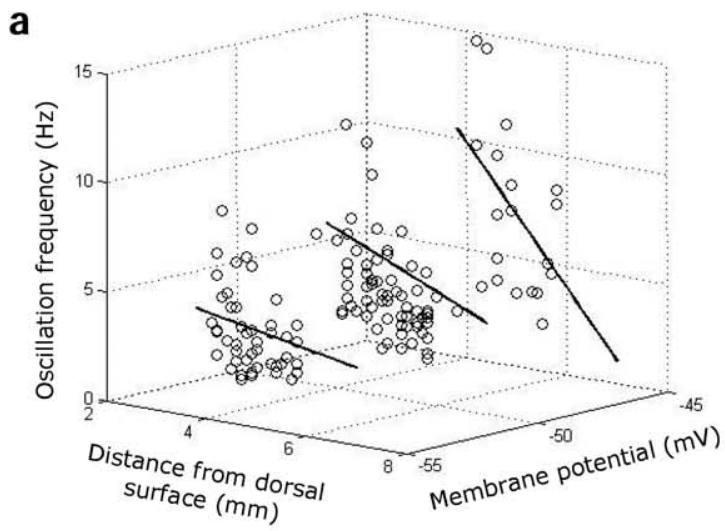

b1

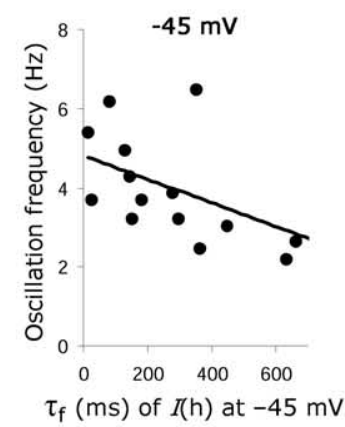

b2

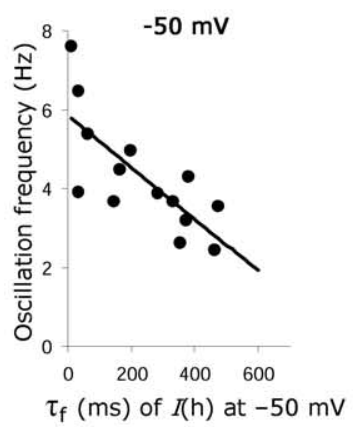

b3

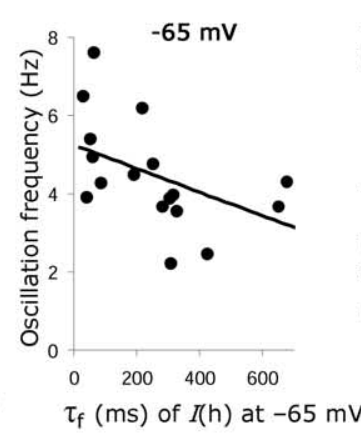

C

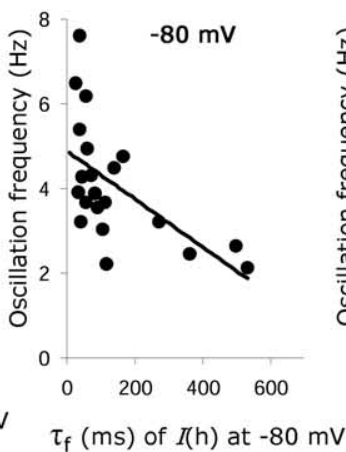

d

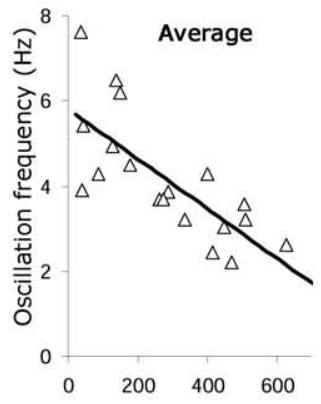

$\tau_{\mathrm{f}}(\mathrm{ms})$ of $I(\mathrm{~h})$, average

Figure 6. Subthreshold membrane potential oscillation frequency changes along dorsal-ventral axis and correlates with the time constant of $I_{\mathrm{h}}$. $\boldsymbol{a}$, The mean frequency of subthreshold oscillations is higher in dorsal compared with ventral cells at -50 and $-45 \mathrm{mV}$. Membrane oscillations are similar in both dorsal and ventral portions of medial entorhinal cortex at $-55 \mathrm{mV}$. $\boldsymbol{b}$, The frequency of subthreshold oscillations at $-50 \mathrm{mV}$ correlates with the time constant of $\mathrm{h}_{\mathrm{h}}$ at a voltage of $-45 \mathrm{mV}(\boldsymbol{b} 1),-50 \mathrm{mV}(\boldsymbol{b} \mathbf{2})$, and $-65 \mathrm{mV}(\boldsymbol{b} 3)$. $\boldsymbol{c}$, At a voltage of $-80 \mathrm{mV}$, the time constant of $I_{h}$ correlates with the frequency of membrane oscillations at $-50 \mathrm{mV}$, but the data points begin to cluster together. $d$, The average time constant of $I_{\mathrm{h}}$ at -45 , -50 , and $-65 \mathrm{mV}$ correlates with the frequency of subthreshold oscillations at $-50 \mathrm{mV}$.

from layer II stellate cells at different locations along the dorsal to ventral axis of the medial entorhinal cortex. The time constant of both the fast and slow component of $I_{\mathrm{h}}$ is significantly faster for dorsal versus ventral stellate cells. The difference in time constant observed in voltage clamp correlates with the difference in frequency of membrane potential oscillations observed in current-clamp recordings near firing threshold in the same neurons, and correlates with the difference in time constant of the sag response to hyperpolarizing current injection.

The experimental correlations strongly support the hypothesis that faster time constants of the activation kinetics of $I_{\mathrm{h}}$ could underlie the higher frequency of membrane potential oscillations observed in dorsal compared with ventral stellate cells in both this study and previous work (Giocomo et al., 2007). The change in the time constant of $I_{\mathrm{h}}$ also provides a potential mechanism for the difference in the resonance frequency and time constant of sag potential observed along the dorsal-ventral axis (Giocomo et al., 2007), and is consistent with previous studies showing a correlation of resonance frequency and oscillation frequency (Erchova et al., 2004). These results are consistent with previous work showing that membrane potential oscillations in layer II stellate cells require the $I_{\mathrm{h}}$ current (Dickson et al., 2000), simulations showing that oscillations can arise dependent on the fast component of $I_{\mathrm{h}}$ activation (Fransén et al., 2004), and previous research indicating the necessity of a stochastic gating of a persistent sodium channel in addition to the h current (White et al., 1998;
Dorval and White, 2005). Although stellate cells along the dorsal to ventral axis may differ in a number of ways (Garden et al., 2007), the correlation observed in these data indicate that the kinetics of $I_{\mathrm{h}}$ may play a critical role in the change in frequency of the subthreshold membrane potential oscillations along the dorsal-ventral axis.

Previous studies on expression of HCN1 and HCN2 in oocytes have demonstrated that the kinetics of $I_{\mathrm{h}}$ differ depending on the subunit composition of the channel. Cloned HCN1 homomeric, HCN1/HCN2 heteromultimeric, and HCN2 homomeric channels have very different kinetics, such as $I_{\mathrm{h}}$ activation and deactivation time constants (Chen et al., 2001). HCN1 channels have fast activation kinetics, heteromultimeric channels are slower, and HCN2 channels have the slowest activation kinetics (Chen et al., 2001). Therefore, the difference in time constants of $I_{\mathrm{h}}$ found here could be attributable to a systematic difference in the ratio of HCN1 to HCN2 subunits along the dorsal-ventral axis of layer II of medial entorhinal cortex. Immunohistochemical localization shows labeling for HCN1 and HCN2 in layer II of rat medial entorhinal cortex, with apparently greater HCN1 labeling compared with HCN2 (Notomi and Shigemoto, 2004). A lower ratio of HCN1 to HCN2 in ventral cells could allow lower frequency oscillations to dominate the subthreshold response, because HCN1 has been proposed to constrain low-frequency oscillations (Nolan et al., 2007). This proposal for a gradient of expression of HCN proteins is consistent with previous studies showing gradients in expression of proteins such as Eph in structures 
a

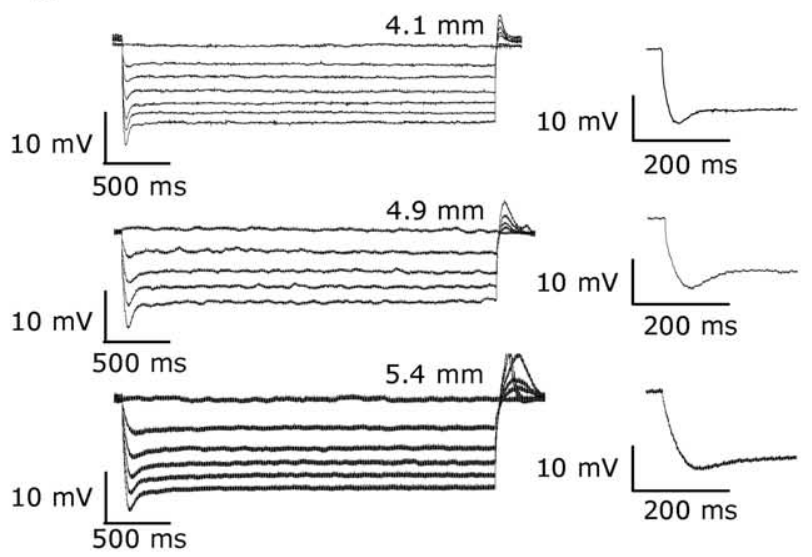

b

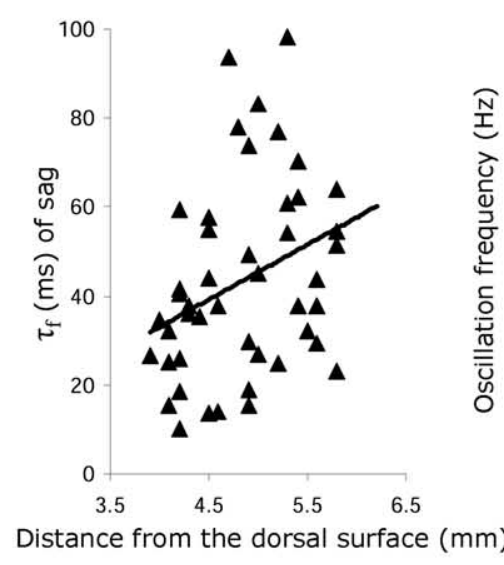

C

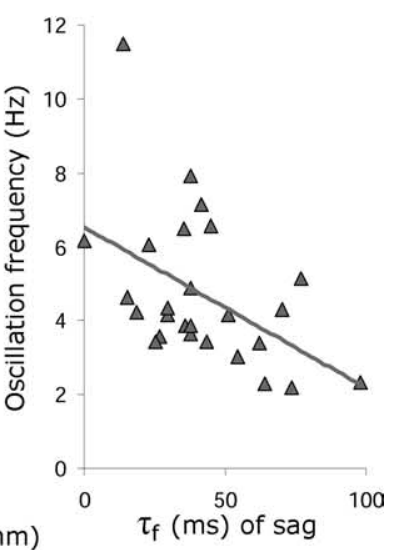

d

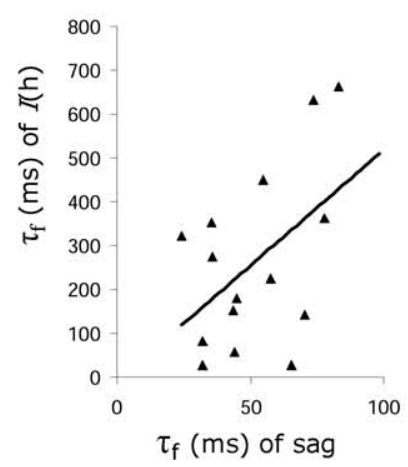

$-50 \mathrm{mV}$

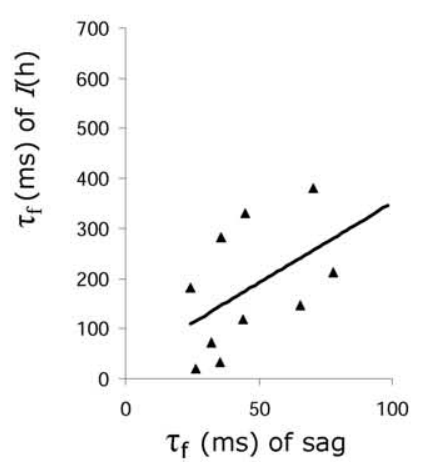

Average

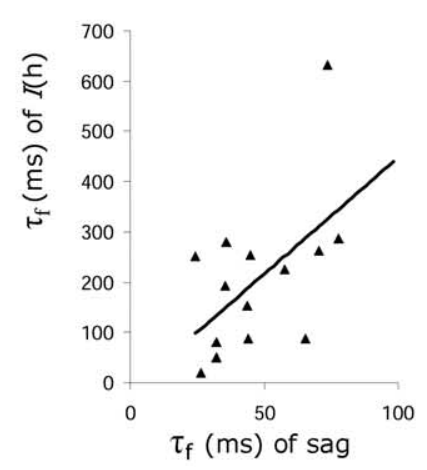

Figure 7. Time constant of sag potential correlates with time constant of $l_{h} \cdot \boldsymbol{a}$, Examples of sag potential from cells located along the dorsal to ventral axis (from top to bottom: $4.2,4.9,5.4 \mathrm{~mm}$ from the dorsal surface). $\boldsymbol{b}$, The time constant of the sag potential (at -75 to $-70 \mathrm{mV}$ ) changes along the dorsal-ventral axis, with faster time constants in dorsal compared with ventral medial entorhinal cortex. $\boldsymbol{c}$, Time constant of the sag at -75 to $-70 \mathrm{mV}$ correlates with the frequency of subthreshold oscillations at $-50 \mathrm{mV}$. $\boldsymbol{d}$, Time constant of the sag potential (at -75 to $-70 \mathrm{mV}$ ) correlates with the time constant of $I_{h}$ at (from left to right) $-45 \mathrm{mV},-50 \mathrm{mV}$, and the average time constant of $\mathrm{h}_{\mathrm{h}}$ for both voltages.

including the septohippocampal system (Brownlee et al., 2000), the cerebral cortex (Mackarehtschian et al., 1999), and the retinotectal system (Goodhill and Richards, 1999).

Our hypothesis suggests that knock-out of the HCN1 channel should result in a loss of differences in membrane potential oscillations along the dorsal-ventral axis of medial entorhinal cortex. This proposed increase in consistency of oscillatory frequency in entorhinal cortex could underlie the enhancement of hippocampal theta rhythm amplitude found with HCN1 knock-outs (Nolan et al., 2004), because membrane potential oscillations can influence network oscillations (Acker et al., 2003). In mice, knock-out of HCN1 has been shown to reduce the sag potential, but was not reported to eliminate subthreshold oscillations; however, this could be attributable to the role of the HCN2 channel or to compensatory changes in other currents in knock-outs (Nolan et al., 2007). In HCN 1 knock-outs, neurons tend to spike rapidly as they approach threshold, preventing measurement of oscillations at the membrane potentials showing maximal dorsalventral differences in our study. The lack of significant difference shown here between oscillations in dorsal versus ventral neurons at $-55 \mathrm{mV}$ suggests that changes in the kinetics of $I_{\mathrm{h}}$ may play a more critical role in frequency of oscillations near threshold. However, knock-out of HCN1 does substantially affect the kinetics of stellate cells (Nolan et al. 2004, 2007), significantly decreasing the resonant frequency, enhancing long-term potentiation, and changing the properties of the action potential (e.g., the afterhyperpolarization and interspike interval), suggesting that the conductances generated by the h current play an important in the output of the network. Indeed, although recent work suggests that subthreshold oscillations are attenuated by conductance-based inputs at the soma (Fernandez and White, 2008), $I_{\mathrm{h}}$ may be amplified in distal dendrites in which the magnitude of $I_{\mathrm{h}}$ contributions may proportionally increase along the proximal to distal portions of dendrites (Magee, 1998).

These differences in $I_{\mathrm{h}}$ time constants along the dorsalventral axis could underlie differences in grid cell properties observed along the same axis in layer II of medial entorhinal cortex (Hafting et al., 2005; Sargolini et al., 2006), including the size and spacing of grid cell firing fields, dependent on its effect on the frequency of subthreshold oscillations. Grid cell firing properties are effectively simulated in a model using interference between membrane potential oscillations regulated by head direction input to single neurons (Burgess et al., 2007). In this model, differences in the spacing and size of simulated firing fields on the dorsal-ventral axis can be obtained by altering either the baseline oscillation frequency of neurons (Burgess et al., 2007; Giocomo et al., 2007; Hasselmo et al., 2007), or by altering the slope of the change in frequency with voltage, consistent with the difference in slope visible in Figure $6 a$. In addition, analysis suggests that the slow time 
constant of h current underlies oscillations matching the time course of the amplitude envelope attributable to interference of oscillations caused by the fast time constant of h current. Thus, this model demonstrates a potential direct link between the time constants of $I_{\mathrm{h}}$ activation, the frequency of membrane potential oscillations, and the physiological properties of grid cells in behaving rats. A prediction of this framework is that pharmacological blockade or genetic disruption of $I_{\mathrm{h}}$ should alter the response properties of grid cells in layer II of medial entorhinal cortex. In particular, selective knock-out of HCN1 should reduce the differences in grid cell field size and spacing along the dorsal-ventral axis of medial entorhinal cortex. As an alternative to this theory, the differences in h current kinetics shown here could contribute to differences in grid cell properties through other mechanisms proposed to underlie grid cell firing responses (Burak and Fiete, 2006; Fuhs and Touretzky, 2006; McNaughton et al., 2006).

\section{References}

Acker CD, Kopell N, White JA (2003) Synchronization of strongly coupled excitatory neurons: relating network behavior to biophysics. J Comput Neurosci 15:71-90.

Alonso A, Klink R (1993) Differential electroresponsiveness of stellate and pyramidal-like cells of medial entorhinal cortex layer II. J Neurophysiol 70:128-143.

Alonso A, Llinás RR (1989) Subthreshold Na-dependent theta-like rhythmicity in stellate cells of entorhinal cortex layer II. Nature 342:175-177.

Barry C, Hayman R, Burgess N, Jeffery KJ (2007) Experience-dependent rescaling of entorhinal grids. Nat Neurosci 10:682-684.

Brownlee H, Gao PP, Frisen J, Dreyfus C, Zhou R, Black IB (2000) Multiple ephrins regulate hippocampal neurite outgrowth. J Comp Neurol 425:315-322.

Burak Y, Fiete I (2006) Do we understand the emergent dynamics of grid cell activity? J Neurosci 26:9352-9354; discussion 9354.

Burgess N, Barry C, O'Keefe J (2007) An oscillatory interference model of grid cell firing. Hippocampus 17:801-812.

Chen S, Wang J, Siegelbaum SA (2001) Properties of hyperpolarizationactivated pacemaker current defined by coassembly of HCN1 and HCN2 subunits and basal modulation by cyclic nucleotide. J Gen Physiol 117:491-504.

Chen S, Wang J, Zhou L, George MS, Siegelbaum SA (2007) Voltage sensor movement and cAMP binding allosterically regulate an inherently voltage-independent closed-open transition in HCN channels. J Gen Physiol 129:175-188.

Dickson CT, Alonso A (1997) Muscarinic induction of synchronous population activity in the entorhinal cortex. J Neurosci 17:6729-6744.

Dickson CT, Magistretti J, Shalinsky MH, Fransén E, Hasselmo ME, Alonso A (2000) Properties and role of $\mathrm{I}(\mathrm{h})$ in the pacing of subthreshold oscillations in entorhinal cortex layer II neurons. J Neurophysiol 83:2562-2579.

Dorval AD Jr, White JA (2005) Channel noise is essential for perithreshold oscillations in entorhinal stellate neurons. J Neurosci 25:10025-10028.

Eckert R, Lux HD (1976) A voltage-sensitive persistent calcium conductance in neuronal somata of Helix. J Physiol 254:129-151.

Erchova I, Kreck G, Heinemann U, Herz AV (2004) Dynamics of rat entorhinal cortex layer II and III cells: characteristics of membrane potential resonance at rest predict oscillation properties near threshold. J Physiol 560:89-110.

Fernandez FR, White JA (2008) Artificial synaptic conductances reduce subthreshold oscillations and periodic firing in stellate cells of the entorhinal cortex. J Neurosci 14:3790-3803.

Fransén E, Alonso AA, Dickson CT, Magistretti J, Hasselmo ME (2004) Ionic mechanisms in the generation of subthreshold oscillations and action potential clustering in entorhinal layer II stellate neurons. Hippocampus 14:368-384.

Fuhs MC, Touretzky DS (2006) A spin glass model of path integration in rat medial entorhinal cortex. J Neurosci 26:4266-4276.

Fyhn M, Hafting T, Treves A, Moser MB, Moser EI (2007) Hippocampal remapping and grid realignment in entorhinal cortex. Nature 446:190-194.
Garden DLF, Dodson PD, White MD, Nolan MF (2007) The integrative properties of stellate cells in the medial entorhinal cortex differ according to their location along the dorsal-ventral axis. Soc Neurosci Abstr 33:251.257.

Gasparini S, DiFrancesco D (1997) Action of the hyperpolarizationactivated current (Ih) blocker ZD7288 in hippocampal CA1 neurons. Pflugers Arch 435:99-106.

Gill CH, Brown JT, Shivji N, Lappin SC, Farmer C, Randall A, McNaughton NC, Cobb SR, Davies CH (2006) Inhibition of Ih reduces epileptiform activity in rodent hippocampal slices. Synapse 59:308-316.

Giocomo LM, Zilli EA, Fransén E, Hasselmo ME (2007) Temporal frequency of subthreshold oscillations scales with entorhinal grid cell field spacing. Science 315:1719-1722.

Gómez-Lagunas F (1999) Barium inhibition of the collapse of the Shaker $\mathrm{K}^{+}$conductance in zero $\mathrm{K}^{+}$. Biophys J 77:2988-2998.

Goodhill GJ, Richards LJ (1999) Retinotectal maps: molecules, models and misplaced data. Trends Neurosci 22:529-534.

Hafting T, Fyhn M, Molden S, Moser MB, Moser EI (2005) Microstructure of a spatial map in the entorhinal cortex. Nature 436:801-806.

Hagiwara S, Takahashi K (1967) Surface density of calcium ions and calcium spikes in the barnacle muscle fiber membrane. J Gen Physiol 50:583-601.

Hamam BN, Amaral DG, Alonso AA (2002) Morphological and electrophysiological characteristics of layer $\mathrm{V}$ neurons of the rat lateral entorhinal cortex. J Comp Neurol 451:45-61.

Harris NC, Constanti A (1995) Mechanism of block by ZD 7288 of the hyperpolarization-activated inward rectifying current in guinea pig substantia nigra neurons in vitro. J Neurophysiol 74:2366-2378.

Harris NC, Libri V, Constanti A (1994) Selective blockade of the hyperpolarization activated cationic current (Ih) in guinea pig substantia nigra pars compacta neurones by a novel bradycardic agent, Zeneca ZM 227189. Neurosci Lett 176:221-225.

Hasselmo ME, Giocomo LM, Zilli EA (2007) Grid cell firing may arise from interference of theta frequency membrane potential oscillations in single neurons. Hippocampus 17:1252-1271.

Inaba Y, Biagini G, Avoli M (2006) The h current blocker ZD7288 decreases epileptiform hyperexcitability in the rat neocortex by depressing synaptic transmission. Neuropharmacology 51:681-691.

Klink R, Alonso A (1997) Morphological characteristics of layer II projection neurons in the rat medial entorhinal cortex. Hippocampus 7:571-583.

Kretschmannova K, Gonzalez-Iglesias AE, Tomić M, Stojilkovic SS (2006) Dependence of hyperpolarization-activated cyclic nucleotidegated channel activity on basal cyclic adenosine monophosphate production in spontaneously firing GH3 cells. J Neuroendocrinol 18:484-493.

Maccaferri G, McBain CJ (1996) The hyperpolarization-actviated current (Ih) and its contribution to pacemaker activity in rat CA1 hippocampal stratum oriens-alveus interneurones. J Physiol 497:119-130.

Mackarehtschian K, Lau CK, Caras I, McConnell SK (1999) Regional differences in the developing cerebral cortex revealed by ephrin-A5 expression. Cereb Cortex 9:601-610.

Magee JC (1998) Dendritic hyperpolarization-activated currents modify the integrative properties of hippocampal CA1 pyramidal neurons. J Neurosci 18:7613-7624.

McNaughton BL, Battaglia FP, Jensen O, Moser EI, Moser MB (2006) Path integration and the neural basis of the "cognitive map." Nat Rev Neurosci 7:663-678.

Neher E (1992) Correction for liquid junction potentials in patch clamp experiments. Methods Enzymol 207:123-131.

Nolan MF, Malleret G, Dudman JT, Buhl DL, Santoro B, Gibbs E, Vronskaya S, Buzsáki G, Siegelbaum SA, Kandel ER, Morozov A (2004) A behavioral role for dendritic integration: HCN1 channels constrain spatial memory and plasticity at inputs to distal dendrites of CA1 pyramidal neurons. Cell 119:719-732.

Nolan MF, Dudman JT, Dodson PD, Santoro B (2007) HCN1 channels control resting and active integrative properties of stellate cells from layer II of the entorhinal cortex. J Neurosci 27:12440-12451.

Notomi T, Shigemoto R (2004) Immunohistochemical localization of Ih channel subunits, HCN1-4, in the rat brain. J Comp Neurol 417:241-276.

Paxinos G, Watson C (1998) The rat brain in stereotaxic coordinates. San Diego: Academic. 
Sargolini F, Fyhn M, Hafting T, McNaughton BL, Witter MP, Moser MB, Moser EI (2006) Conjunctive representation of position, direction, and velocity in entorhinal cortex. Science 312:758-762.

Standen NB, Stanfield PR (1978) A potential and time-dependent blockade of inward rectification in frog skeletal muscle fibres by barium and strontium ions. J Physiol 280:169-191.

Tahvildari B, Alonso A (2005) Morphological and electrophysiological properties of lateral entorhinal cortex layers II and III principal neurons. J Comp Neurol 491:123-140.

Walsh KB, Zhang J (2008) Neonatal rat cardiac fibroblasts express three types of voltage-gated $\mathrm{K}^{+}$channels: regulation of transient outward current by protein kinase C. Am J Physiol Heart Circ Physiol 294:H1010-H1017.
White JA, Budde T, Kay AR (1995) A bifurcation analysis of neuronal subthreshold oscillations. Biophys J 69:1203-1217.

White JA, Klink R, Alonso A, Kay AR (1998) Noise from voltage-gated ion channels may influence neuronal dynamics in the entorhinal cortex. J Neurophysiol 80:262-269.

Witter MP, Moser EI (2006) Spatial representation and the architecture of the entorhinal cortex. Trends Neurosci 29:671-678.

Yoshida M, Alonso A (2007) Cell-type specific modulation of intrinsic firing properties and subthreshold membrane oscillations by the $\mathrm{M}(\mathrm{Kv} 7)$-current in neurons of the entorhinal cortex. J Neurophysiol 98:2779-2794.

Zhang K, Peng BW, Sanchez RM (2006) Decreased Ih in hippocampal area CA1 pyramidal neurons after perinatal seizure-inducing hypoxia. Epilepsia 47:1023-1028. 